\section{FLUORIDATION ADVOCATE RECEIVES SPECIAL AWARD}

Jerry Read, Head of Oral Health and Dental Education at the Department of Health (DH), has received a Special Service Award from the Faculty of Dental Surgery and the Faculty of General Dental Practice at their joint Diplomates Ceremony in April, for his outstanding contribution to the Faculties and to dentistry as a whole.

Jerry has risen rapidly through the ranks at the $\mathrm{DH}$, taking responsibility for many aspects of dental and oral health including the development of mandatory continuing professional development for dentists and dental care professionals.

'One of Jerry's most notable achievements was his tireless and successful work over many years to promote water fluoridation in the UK,' added FDS Dean, Professor Derrick Willmot.

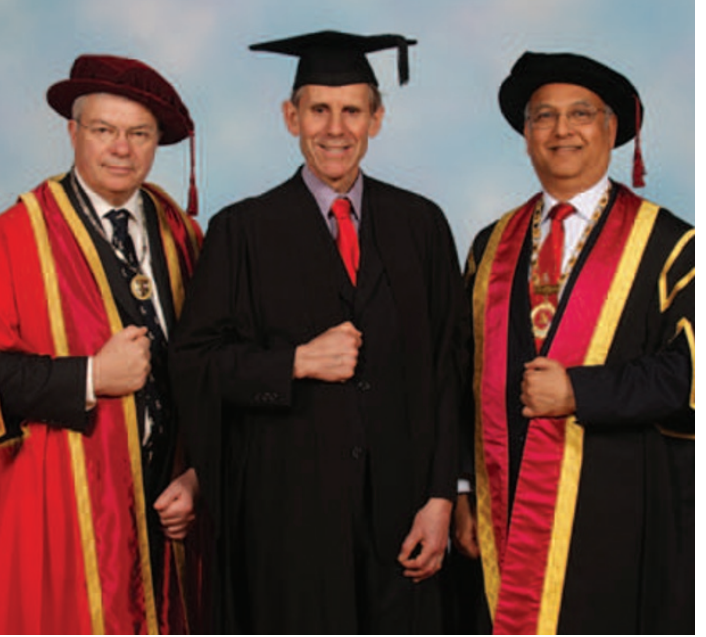

Jerry Read (centre) with Derrick Willmot, FDS Dean (left) and Russ Ladwa, Dean of the FGDP(UK) (right)

\title{
EXPERTS LINED UP FOR SCOTTISH MEETING
}

Two of the most highly respected experts in endodontics and periodontics will be speaking at the British Dental Association (BDA) Scottish Scientific Conference on 9 September 2011 in Dunblane.

Professor Philip Lumley, Professor of Endodontology at the University of Birmingham will provide an overview of contemporary endodontic treatment, the biological basis for endodontic management, factors found in clinical trials on outcomes and a range of contemporary treatment techniques. Professor Ian Needleman, Professor of Restorative Dentistry and Evidence-Based Healthcare at UCL Eastman Dental Institute, will speak on the management of periodontal health in dental practice, treatment objectives, the role of non-surgical periodontal therapy and how to design an effective therapy programme.

For more information on the conference telephone 02075634590 or visit www.bda.org/seminars.

\section{TODDLER NUTRITION MUST BE PRIORITISED}

The Infant \& Toddler Forum - experts in child health, nutrition and development - is stepping up its work to encourage wider recognition and adoption of its Ten steps for healthy toddlers, launched last year to address the lack of simple, consistent guidance on toddler eating habits.

The Ten steps are an easy-to-use guide on what food to offer, what eating behaviours to encourage and how best to manage mealtimes. Endorsed by the Pre-school Learning Alliance, Child Growth Foundation, National Obesity Forum and the British Dental Health Foundation (BDHF), the Ten steps are designed to encourage positive changes to toddler feeding with small easy actions. The BDHF were also involved in the writing and approval of one of the Infant \&t Toddler Forum's factsheets, Protecting toddlers from dental decay.

'As well as being a simple, extremely useful tool for those feeding toddlers at home, the Ten steps is a perfect resource

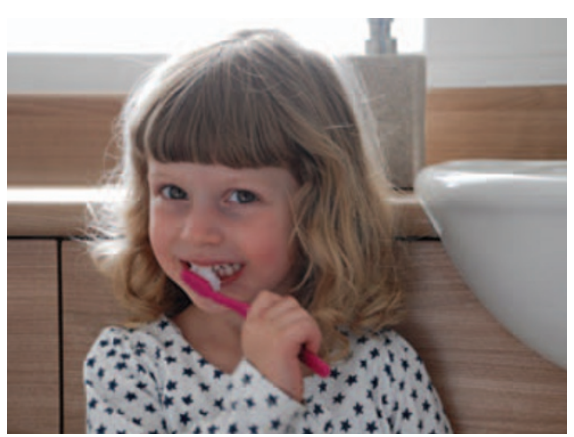

to help implement the Government's public health strategies,' said Dr Atul Singhal, Chair of the Infant \&t Toddler Forum.

Public health is high on the Government's agenda and the recent School Food Trust report highlighted an urgent need for government and all stakeholders, including health practitioners and parents, to work together to address this need and to tackle the epidemic of obesity and diet-related ill health.

To download free resources visit www.infantandtoddlerforum.org.

\section{DENTAL ANXIETY VERY HIGH AMONG HOMELESS}

According to the Smile4Life report launched in May, planning for good oral health should be integrated into national health and homelessness policies in Scotland.

The report is based on a survey of more than 850 homeless people across Scotland and found that homeless people had a higher than normal rate of decayed and missing teeth, suggesting that many attended for dental treatment only when in an emergency and when experiencing pain.

'Dental anxiety among homeless people is about double the rate found in the rest of the population,' said Professor Ruth Freeman of the Dental Health Services Research Unit (DHSRU) at the University of Dundee. 'So we see oral health as being part of the wider set of problems that many homeless people face.'

'This research shows how important it is for dental health services to be considered as a key element of health and homelessness action plans,' commented Robert Aldridge, Chief Executive of Scottish Council for Single Homeless. 